\title{
História
}

\section{Entrevista com Maria Teresa Antunes Albergaria}

\author{
Interview with Maria Teresa Antunes Albergaria
}

\section{Entrevista con Maria Teresa Antunes Albergaria}

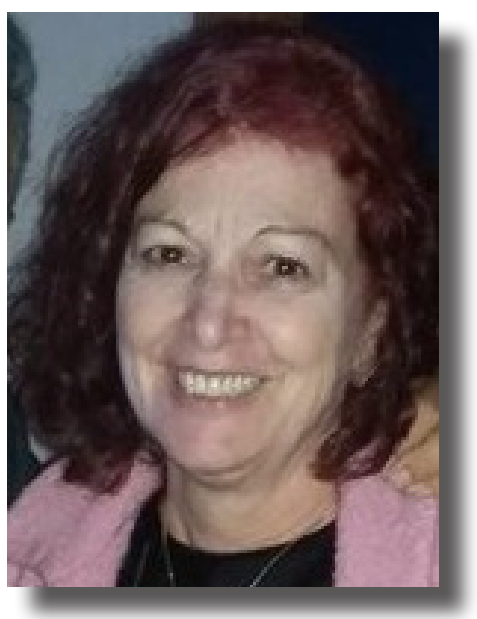

Graduação em Psicologia pela Faculdade Dom Bosco de Filosofia Ciências e Letras e Mestre em Educação pela Pontifícia Universidade Católica do Rio de Janeiro. Professora aposentada, trabalhou na área de Psicologia Escolar e Educacional no curso de Graduação em Psicologia da Universidade Federal de São João del-ReiUFSJ desde 1992.

ENTREVISTADORA: Silvia Maria Cintra da Silva

Silvia: Como se constituiu seu interesse pela área de Psicologia Escolar?

Teresa: Minha história profissional encontra-se entrelaçada com a Psicologia e a Educação. Oriunda de uma família de nove mulheres, das quais sete eram professoras primárias, acabei convivendo diariamente com as questões educacionais por elas vividas em suas práticas educativas. Outra influência importante foi o fato de ter herdado de uma tia paterna, que frequentou a Escola de Aperfeiçoamento de Helena Antipoff, todo seu acervo de Educação dessa época. Lembro-me do contato com os livros de Psicologia do Desenvolvimento, de textos e apostilas sobre Educação e muitos outros documentos que guardei por um tempo como herança. Assim, o contato com as questões educativas no convívio familiar e a oportunidade de exercer a docência logo após me formar em Psicologia em 1981, mesmo não tendo cursado o Magistério como minhas irmãs, contribuíram para minha escolha da Psicologia Escolar como área de atuação na Psicologia. Foi por acreditar que existe esperança ao se trabalhar com Educação e que ela pode transformar visões de mundo e realidades sociais que trabalhei nestes últimos 30 anos com em Psicologia Escolar e Educacional.

Silvia: Como ocorreu sua formação profissional na área? Quais foram os seus principais interlocutores?

Teresa: Minha formação ocorreu na Faculdade Dom Bosco de Filosofia Ciências e Letras em São João del-Rei, que oferecia apenas duas disciplinas intituladas Psicologia Escolar e Problemas de Aprendizagem I, II que abordavam o trabalho do psicólogo na escola com ênfase na atuação diante dos problemas de aprendizagem tais como dislalia, dislexia, dentre outros tão enfatizados no final da década 
de 1970. As leituras preliminares foram livros em Psicologia Escolar traduzidos da literatura norte-americana, o livro Introdução à Psicologia Escolar de Maria Helena Novaes, apostilas sobre problemas de aprendizagem mimeografadas retiradas do livro Distúrbios de Aprendizagem (1973) de Doris J. Johnson e Helmer R. Myklebust, dentre outros. A oportunidade de estagiar na área veio com um trabalho em Psicopedagogia Clínica numa clínica de Atendimento Psicopedagógico Descentralizada (APD). Nesta, as crianças e adolescentes com problemas escolares na rede pública eram encaminhadas para o atendimento psicopedagógico, passando primeiro por uma triagem que contemplava a realização de uma anamnese com os pais ou responsáveis sobre o aluno, a realização de testes de inteligência, personalidade, coordenação visomotora, lateralidade, percepção, prontidão e entrevistas semidirigidas com pais e professoras. Após o levantamento dos resultados obtidos nesses instrumentos era feito o diagnóstico e prognóstico do caso, muitas vezes culminando com a indicação para uma psicoterapia, trabalhos de reeducação psicomotora tomando como referência os trabalhos de Ana Maria Poppovic e ainda encaminhamento para profissionais tais como fonoaudiólogo, neurologista e pedagogo, dentre outros. O aluno com dificuldades de escolarização era, nessa época, o único a ser atendido no trabalho de reeducação psicomotora, cabendo algumas conversas com os pais e professores dos alunos quando se fizesse necessário. Mas foi com a inserção no trabalho docente, primeiramente atuando no Magistério de $2^{\circ}$ Grau para a formação de professores e no Ensino Técnico em Secretariado e Enfermagem lecionando a disciplina Psicologia da Educação, de 1981 a 1984, que fui reconstruindo minha formação profissional. O contato com as ideias de Paulo Freire, o livro de Lannoy Dorin e outros que me fogem à memória, utilizados nessa época, me serviram de guia para meu trabalho. No inicio do exercício da docência no ensino superior em 1987, trabalhei com as disciplinas Psicologia Escolar e Psicologia da Aprendizagem, época em que precisei estudar muito, sendo um período de descobertas e de grande sofrimento, pois pude perceber como a graduação muito pouco tinha contribuído para minha formação na área escolar. Assim, para trabalhar na área participei de eventos relacionados à Educação acompanhando por muitos anos os encontros da ANPed em Caxambu, para me inteirar das discussões sobre as questões educacionais, dos CONEPs que discutiam as politicas públicas de educação e ajudavam na construção de propostas alternativas para a Educação no Brasil. Participava também de eventos em Psicologia que tinham uma sessão dedicada à Psicologia Escolar, nos quais tomei contato com as obras de Maria Helena Novaes, e principalmente as de Maria Helena Souza Patto que me ajudaram a construir uma visão mais crítica da Psicologia Escolar. Outras psicólogas escolares que influenciaram minha formação profissional foram Raquel Souza Lobo Guzzo, Adriana Marcondes Machado e Vera Lúcia Trevisan de Souza. Por fim, a parceria com o Professor Dener Luiz da Silva (UFSJ) nos dez anos em que trabalhamos com a Psicoeducar (Equipe de Psicologia Escolar e Educacional da
UFSJ) muito contribuiu para minha formação e atuação profissional. Acredito que minha formação profissional ocorreu ao longo de todo o meu trabalho e se fortalecia à medida que enfrentava novos desafios nos trabalhos práticos das disciplinas oferecidas no curso de Psicologia e licenciaturas, nos projetos de extensão e supervisões de estágios em escolas publicas de ensino fundamental, médio, ensino superior, no sistema prisional e nas atividades direcionadas às professoras e familiares, nos trabalhos em creches e pré-escolas da cidade.

Silvia: Com que temáticas você trabalhou e trabalha na área? Realiza pesquisas?

Teresa: No meu trabalho em Psicologia Escolar/ Educacional transitei por diferentes temáticas, iniciei com a formação de professores primeiramente no Magistério de $2^{\circ}$ Grau (Curso Normal) e depois nas licenciaturas em Pedagogia, História, Filosofia, Matemática, Letras da UFSJ, e buscava trabalhar com os graduandos questões do cotidiano escolar possibilitando a ressignificação do conhecimento teórico de Educação e Psicologia em suas práticas. Nas licenciaturas, a afetividade, a relação aluno-professor e a relação família-escola foram temáticas que se faziam presentes não só nas aulas, mas em palestras, cursos de capacitação, dentre outros momentos da vida acadêmica. Outra temática trabalhada, a formação e atuação do psicólogo escolar e educacional, se fez presente tanto em sala de aula, nos estágios curriculares obrigatórios, mas principalmente nos Projetos de Extensão desenvolvidos por 19 anos na UFSJ. Nos Projetos de Extensão desenvolvidos em escolas públicas, creches e pré-escola fazíamos primeiramente uma cartilha informando sobre o trabalho do psicólogo escolar/ educacional e ela era distribuída para todos os envolvidos no projeto. Temas como jogos, brincadeiras, papéis da família e da escola, adolescência (namoro, sexualidade, relação com os pais etc.) e as drogas eram demandados e trabalhados com alunos, professores e pais. Nos projetos de extensão as politicas públicas de Educação, principalmente o Projeto Acelerar para Vencer- PAV da Secretaria Estadual de Educação de Minas Gerais foram temas bastante estudados e debatidos. Nos estágios curriculares, as supervisões tinham um momento de grupo de estudos, com textos sobre os estagiários de Psicologia na escola, o papel da supervisão e dos estagiários, o processo da avaliação do mesmo e as temáticas demandadas pela escola que eram objeto de pesquisa, reflexão e debate dos estagiários. Para cada atividade a ser desenvolvida no estágio eram trabalhados textos referentes àquela temática e pensadas coletivamente as ações a serem realizadas. Temáticas mais frequentes eram sobre os alunos, a relação escola-família, stress dos professores e da direção da escola, dentre outras.

Trabalhos de consultoria e assessoria em Psicologia Escolar e Educacional ocorreram em escolas públicas do ensino fundamental e dentro da UFSJ. Lembro, por exemplo, o trabalho de alunos de Psicologia com uma equipe de graduandos de uma licenciatura que atuavam num estágio como docentes; os alunos de Psicologia assistiam e depois 
se reuniam para discutir sobre o vivenciado, para dialogar sobre o funcionamento da equipe e em rodas de conversa discutiam-se as temáticas presentes no cotidiano escolar e as contribuições da Psicologia neste diálogo. No trabalho em creches e pré- escolas as temáticas do desenvolvimento infantil, dificuldades de aprendizagem e a relação famíliaescola foram bastante trabalhadas tanto em minicursos para professoras, crecheiras e familiares. O trabalho do psicólogo escolar em uma escola do sistema prisional se constituiu numa rica experiência pessoal e profissional, tanto para as alunas-estagiárias quanto para mim como orientadora. Temas como educação no sistema prisional, a relação professor- aluno nessa escola, o papel do psicólogo escolar, o significado do estudar para os detentos permearam os estudos e as discussões presentes no trabalho.

Meu primeiro contato com a pesquisa se inicia no mestrado em Educação com o trabalho "Práticas Educativas em Famílias de Camadas Médias e Processos de Escolarização dos Filhos: o caso dos professores da FUNREl" em 2000. Meu interesse pelo tema da relação família-escola foi suscitado pela minha experiência profissional (estágios, projetos de extensão, palestras, consultoria e assessoria em escolas publicas), pelas observações guiadas pelo olhar psicológico e redimensionado por leituras sociológicas e por várias discussões ocorridas nas reuniões da pesquisa "Trajetórias Escolares e Processos de Socialização", coordenada pelas Dras. Zaia Brandão e Isabel Léllis, professoras da PUC- Rio. Tinha como objetivo captar as relações entre pais professores da FUNREI e práticas educativas a que são submetidos seus filhos. Em 2006, juntamente com a querida Professora Dra. Elizabeth de Melo Bonfim realizamos uma pesquisa intitulada "A Análise e Recuperação do Acervo do Laboratório de Psicologia da Faculdade Dom Bosco de Filosofia, Ciências e Letras de São João del-Rei" e seus resultados foram compilados em dois catálogos: Catálogo Geral do Acervo do Laboratório de Psicologia da Faculdade Dom Bosco de Filosofia, Ciências e Letras de São João del-Rei e o Catálogo Referencial-Descritivo do Acervo do Laboratório de Psicologia da Faculdade Dom Bosco de Filosofia, Ciências e Letras de São João del-Rei. O Centro de Documentação em Psicologia (CEDOC) da UFSJ surge a partir dos frutos deste trabalho que continua dando frutos nos estudos desenvolvidos por mestrandos em Psicologia e nos trabalhos de Iniciação Científica coordenados por professores do LAPIP/UFSJ. Com esta pesquisa foi possível a recuperação de parte da história da Psicologia Escolar e Educacional em Minas Gerais.

Silvia: Que experiências você cita como mais significativas no campo da Psicologia Escolar e que influenciaram a sua prática profissional?

Teresa: Experiências diversificadas ocorreram nos estágios supervisionados nas escolas em trabalhos com professores, alunos, e familiares. O PAIQUE (Procedimento de Avaliação e Intervenção das Queixas Escolares) desenvolvido pelas Dras. Marisa Maria Neves e Sandra Francesca Conte de Almeida no Distrito Federal foi objeto de estudo nos estágios desenvolvidos e, respeitando as especificidades locais, serviu de base para várias intervenções em diferentes escolas públicas, principalmente no trabalho junto às classes de aceleração, presentes no Projeto Acelerar para Vencer (PAV), política implementada pela Secretaria Estadual de Educação de Minas Gerais, a partir de 2008. Os trabalhos e textos da Dra. Adriana Marcondes Machado e em especial o Projeto de Plantão Institucional, um dispositivo criador desenvolvido na USP junto a professoras, coordenadoras e diretoras de escolas paulistas muito contribuíram para os trabalhos desenvolvidos nas escolas por nós atendidas. $E$ ainda as pesquisas- intervenções desenvolvidas pela Dra. Vera Lucia Trevisan serviram de apoio para os trabalhos com diretoras das escolas trabalhadas.

Silvia: Quais seriam, ainda, as principais questões a serem enfrentadas pela Psicologia Escolar e Educacional, do seu ponto de vista?

Teresa: Primeiramente vejo a necessidade de construção de práticas que contemplem o conhecimento multidisciplinar, o trabalho em equipe, o desenvolvimento de ações coletivas, preventivas e de promoção da saúde. Outro desafio é a construção de conhecimentos e atuações que contribuam para a elaboração de políticas educacionais, para a formação continuada de professores, para os processos de inclusão no ensino regular e para o trabalho investigativo (pesquisa-ação) no contexto educacional.

Silvia: Como você vê a formação do psicólogo para atuar no campo educacional?

Teresa: Acho que novas perspectivas de formação do psicólogo para atuar no campo educativo estão sendo construídas e concretizadas, principalmente por docentes comprometidos com uma Psicologia Escolar Preventiva. A produção bibliográfica na área se apresenta bastante extensa, mas sinto que falta aos docentes e graduandos maior contato com esta diversidade de ideias e trabalhos. AABRA$\mathrm{PEE}$ e os congressos nacionais e internacionais em Psicologia Escolar e Educacional estão acontecendo e trazendo frutos, os trabalhos divulgados na ANPEP também; assim, um maior acesso aos conhecimentos produzidos vem sendo disponibilizado aos profissionais da área e aos estudantes que precisam se apropriar e dialogar com eles. Mas ainda avançamos pouco na formação com relação aos estágios, que ocorrem muitas vezes no final do curso, com supervisões que não ajudam na construção do fazer do psicólogo nas instituições educativas. Os professores universitários da área, muitas vezes, imersos em diferentes atividades acadêmicas, não conseguem vivenciar a realidade educativa, fato que influencia no acompanhamento dos estágios. Acredito que a formação específica na área já não é suficiente para o atendimento das demandas sociais direcionadas ao psicólogo escolar. Assim, torna-se necessário o oferecimento de conhecimentos multidisciplinares, principalmente relacionados à Educação e às Ciências da Educação, conhecimentos e ações para um trabalho em equipe, bem como desenvolver no aluno uma postura ética e profissional que o leve à refle- 
xão sobre os desdobramentos de sua atuação. Acredito que uma experiência de formação em Psicologia Escolar deve possibilitar ao discente de Psicologia assumir uma postura crítica e reflexiva em sua atuação, enfatizar a necessidade de parceria com os atores envolvidos no cenário educacional, para que juntos construam estratégias que se pautem em ações individuais e coletivas em consonância com a ética profissional e com o respeito aos direitos humanos.

Silvia: Gostaria de acrescentar mais alguma consideração ou reflexão?

Teresa: Trabalhar em Psicologia Escolar e Educacional por estes longos anos me fez sentir o quanto o trabalho do psicólogo nas instituições educativas se faz necessário. Como dizia aos meus alunos, estagiários e bolsistas de extensão, não existe modelo pronto para ser seguido, daí talvez a dificuldade de alguns em atuar na área. Foram muitos trabalhos e experiências gratificantes, outras algumas vezes bastantes sofridas, que me levaram a grandes des- cobertas, mas também rever erros, desencontros e mal entendidos presentes nas relações interpessoais vivenciadas e nas atividades desenvolvidas com alunos de Psicologia, professoras, especialistas, diretoras e familiares. Minha paixão pelos trabalhos de extensão universitária desenvolvidos em escolas públicas desde 1995 enriqueceram profundamente minha atuação profissional e possibilitaram o contato mais próximo com as realidades educativas. Gostaria de agradecer a todos que me ajudaram nesta trajetória (alunos, estagiários e bolsistas em Psicologia, colegas de trabalho, professoras, especialistas, diretoras, alunos das escolas públicas e seus familiares) e que tanto contribuíram e influenciaram na minha experiência de vida e profissional. "Se muito vale o já feito, mais vale o que será, e o que foi feito é preciso conhecer para melhor prosseguir", (Milton Nascimento) essa ideia me inspira na busca pelo conhecimento e pelo meu crescimento profissional na área de Psicologia Escolar e Educacional.

Maria Teresa Antunes Albergaria (mtantunesa@gmail.com) - Universidade Federal de São João del-Rei.

Silvia Maria Cintra da Silva (silvia_ufu@hotmail.com) - Universidade Federal de Uberlândia.

Presidente Atual da ABRAPEE, professora do Instituto de Psicologia da Universidade Federal de Uberlândia. 